\title{
Como a comunidade científica portuguesa analisa a educação profissional
}

\author{
Marilandi Maria Mascarello Vieira* \\ Graça Simões de Carvalho** \\ Maria Cristina Pansera de Araújo*** \\ Rosa Branca Cameira Trancana Pereira****
}

\section{Resumo}

A educação profissional (EP) tem tido grande incremento de oferta em Portugal e no Brasil, configurando-se como importante campo de pesquisa. $\mathrm{O}$ artigo analisa a produção acadêmica da comunidade científica portuguesa sobre a EP. O corpus foi constituído por 22 trabalhos que estão disponíveis em repositórios de universidades e de outras instituições portuguesas. A análise dos trabalhos foi realizada por meio da análise de conteúdo de Bardin (2002), a qual permitiu constatar que a produção incide principalmente sobre cursos profissionais do ensino secundário, por pesquisadores portugueses, porém com forte presença de estudantes de pós-graduação brasileiros como coautores e as temáticas foram: (a) caracterização dos cursos; (b) formação de professores; (c) políticas e currículo; e (d) gestão administrativa e pedagógica dos cursos. A pesquisa demonstra que os estudos sobre EP em Portugal são incipientes e exploratórios, havendo necessidade de aprofundar o tema.

Palavras-chave: Educação profissional; Cursos profissionais; Cursos Técnicos Superiores Profissionais.

\footnotetext{
* Mestre em Educação e Mestre em Direito. Doutora em Educação nas Ciências - UNIJUI. Professora do Instituto Federal de Educação, Ciência e Tecnologia do Rio Grande do Sul, Campus Sertão. E-mail: marilandi. vieira@sertao.ifrs.edu.br

** Doutora em Biologia pela Universidade de Aveiro - PT. Professora pesquisadora do Instituto de Educação e Diretora do Centro de Investigação e Estudos da Criança da Universidade do Minho. E-mail: graca@ ie.uminho.pt

*** Doutora em Genética e Biologia Molecular - UFRGS. Professora pesquisadora do Programa de Pós-Graduação em Educação nas Ciências - UNIJUI. E-mail: pansera@unijui.edu.br

**** Doutora no ramo de Estudos da Criança, área de conhecimento de Estudo do Meio Físico. Professora e subdiretora da Escola Superior de Educação, Comunicação e Desporto do Instituto Politécnico da Guarda - Portugal. E-mail: rtracana@ipg.pt
} 


\section{How the portuguese science community analyzes professional education}

\section{Cómo la comunidad científica portuguesa analisa la educación profesional}

\section{Abstract}

The professional education (PE) has greatly increased supply in Portugal and Brazil, setting up an important field of research. The paper analyzes the academic production of Portuguese scientific community about PE. The corpus consisted of 22 works which are available in repositories of universities and other Portuguese institutions. The analysis of the works was carried out by the content analysis of Bardin (2002), which allowed to verify that the production focuses mainly on professional courses of secondary education, by Portuguese researches, but with a strong presence of Brazilian postgraduate students as co-authors and the themes were: (a) characterization of courses; (b) teachers formation; (c) policies and curriculum; and (d) administrative and pedagogical management of courses. The research demonstrates that the studies on PE in Portugal are very incipient and exploratory, so that deepen studies on this theme are needed.

Keywords: Professional education; Professional Courses; Professional Technical Higher Education Courses.

\section{Resumen}

La educación profesional (EP) ha tenido un gran incremento de oferta en Portugal y Brasil, configurándose como importante campo de investigación. El artículo analiza la producción académica de la comunidad científica portuguesa sobre EP. El corpus fue constituido por 22 trabajos que están disponibles en repositorios de universidades y de otras instituciones portuguesas. El análisis de los trabajos fue realizado por medio del análisis de contenido de Bardin (2002), la cual permitió constatar que la producción incide principalmente sobre cursos profesionales de la enseñanza secundaria, por investigadores portugueses, pero con fuerte presencia de estudiantes de post-graduación brasileños como coautores y las temáticas fueron: (a) caracterización de los cursos; (b) formación de profesores; (c) políticas y currículo en Brasil y / o Portugal; y (d) gestión administrativa y / o pedagógica de los cursos. La investigación demuestra que los estudios sobre EP en Portugal son incipientes y exploratorios, habiendo necesidad de profundizar el tema.

Palavras clave: Educación profesional; Cursos profesionales; Cursos Técnicos Superiores Profesionales. 


\section{Introdução}

A sociedade atual caracteriza-se pela globalização da economia que originou novos e complexos contextos com mudanças nas formas de organização do trabalho e nas relações de emprego. Assim, a educação profissional passou a constar na agenda governamental de vários países dos continentes europeu e americano devido às novas exigências em termos formativos na educação formal.

A partir da década de 1990, tanto em Portugal (CERQUEIRA; MARTINS, 2011) quanto no Brasil (MACHADO, 2011), os governos passaram a ampliar as oportunidades educacionais nessa modalidade de ensino, o que gerou ampliação da rede de ensino e, por consequência, maior contratação de professores.

A produção acadêmica sobre a educação profissional é um campo do conhecimento que, embora recente, já conta com um considerável histórico que precisa ser conhecido. Nesse novo contexto, o acesso aberto às produções acadêmicas é facilitado pela existência de repositórios das instituições de ensino que armazenam os textos integrais, disponibilizando-os para outras análises dos resultados das investigações.

Considerando essas referências, este artigo apresenta um estudo com a intenção de explicitar o conhecimento produzido pela comunidade científica portuguesa acerca da educação profissional em Portugal. O artigo é constituído por quatro seções: a primeira descreve um breve panorama da organização do sistema de ensino português, enfocando a educação profissional; a segunda explicita o percurso metodológico do estudo; a terceira apresenta e discute os resultados e, por fim, a última trata das conclusões do estudo.

\section{Sistema educativo e educação profissional em Portugal}

\subsection{Sistema educativo português em traços gerais}

Para que se possa compreender o estado do conhecimento sobre educação profissional em Portugal é im- portante explicitar, mesmo que em breves notas, como se encontra organizado o seu sistema educativo e nele o espaço destinado à educação profissional.

Segundo o Ministério da Educação (2007), a partir de 1986, com a aprovação da Lei de Bases do Sistema Educativo (LBSE), este sistema foi organizado em quatro etapas: educação pré-escolar, ensino básico, ensino secundário e ensino superior.

a) Pré-escolar: destinado a crianças entre três e seis anos de idade com frequência facultativa;

b) Ensino Básico: organizado em três ciclos de frequência obrigatória: $1^{\circ} \mathrm{Ciclo}$ - quatro anos de escolaridade $\left(1^{\circ}, 2^{\circ}, 3^{\circ}\right.$ e $4^{\circ}$ ano $)$ - alunos entre os $6 / 7$ e os $9 / 10$ anos; $2^{\circ} \mathrm{Ciclo}$ - dois anos de escolaridade $\left(5^{\circ}\right.$ e $6^{\circ}$ ano) - alunos entre os 10/11 e 11/12 anos; $3^{\circ}$ Ciclo - três anos de escolaridade $\left(7^{\circ}, 8^{\circ}\right.$ e $9^{\circ}$ ano) e alunos entre os $12 / 13$ e $14 / 15$ anos.

c) Ensino Secundário: obrigatório, é organizado de formas diferenciadas, com cursos permeáveis entre si e dupla função: prosseguimento dos estudos e formação profissional para a inserção no mundo do trabalho. Segundo o Ministério da Educação Português (2007, p. 17), o Ensino Secundário organiza-se nas seguintes áreas:

\footnotetext{
Cursos científicos-humanísticos, vocacionados essencialmente para o prosseguimento dos estudos de nível superior;

Cursos Artísticos Especializados, organizados com o objetivo de assegurar formação artística especializada nas áreas de artes visuais, audioviduais, dança e música;

Cursos profissionais, vocacionados fundamentalmente para alunos que pretendam entrar no mundo do trabalho.
}

Os cursos científico-humanísticos podem ser estruturados em quatro áreas: Ciências e Tecnologias, Ciências Socioeconômicas, Línguas e Humanidades e Artes Visuais.

No que diz respeito aos cursos profissionais, estes têm duração de 3100 horas e são constituídos por três componentes de formação: 
1. Sociocultural: Língua Portuguesa, Língua Estrangeira, Área de Integração, Tecnologia da Informação e da Comunicação e Educação Física, totalizando 1.000 horas;

2. Científica: constituída por dois ou três componentes curriculares totalizando 500 horas;

3. Técnica: composta por três a quatro disciplinas que perfazem 1180 horas, além da Formação em Contexto de Trabalho com 420 horas.

Os cursos científicos-humanísticos emitem diploma que permite o prosseguimento de estudos, e os cursos científicos especializados e cursos profissionais emitem diploma com a dupla certificação para efeitos de prosseguimento de estudos e exercício de determinadas atividades profissionais, com certificação de qualificação de nível 3 do Quadro Nacional de Qualificações'.

d) Ensino superior: compreende o ensino politécnico e universitário, ministrado em instituições públicas, privadas ou cooperativas. As universidades formam os licenciados, mestres e doutores e os institutos politécnicos oferecem os Cursos Técnicos Superiores Profissionais (CTSP), as licenciaturas ${ }^{2}$ e os mestrados.

No que concerne a educação profissional há a oferta dos Cursos Profissionais (CP) e dos Cursos Técnicos Superiores Profissionais (CTSP). Os CP são fornecidos pelas escolas secundárias da rede pública ou escolas profissionais públicas ou privadas, sendo que as escolas profissionais fornecem maior número de cursos do que as escolas secundárias por serem mais combativas na atração de alunos. Nestes $\mathrm{CP}$ podem ingressar alunos com o $3^{\circ}$ ciclo do ensino básico concluído (com idade em torno dos 15 anos), e os concluintes obtêm o diploma de ensino secundário e certificação profissional de nível 4. Já os CTSP fornecem formação de nível superior e são ministrados exclusivamente nos institutos politécnicos, tendo duração de dois anos, não conferindo grau acadêmico, mas fornecendo diploma de técnico superior profissional de nível 5, nas áreas específicas. Estes cursos têm a vantagem de os alunos poderem fazer estágio durante um semestre, correspondente a $750 \mathrm{~h}$.

\subsection{Breve histórico da educação profissional em Portugal}

A origem da educação profissional, segundo Cerqueira; Martins (2011), se situa na década de 1980, quando foi introduzida no nível do ensino secundário, por meio do Decreto $n^{\circ} 240 / 80$ de 19 de julho, o $12^{\circ}$ ano estruturado em duas vias - via ensino e via profissionalizante.

Em 1989, ocorreu a reforma do ensino secundário, resultante da Lei de Bases do Sistema Educativo de 1986, e, segundo Cerqueira; Martins (2011, p. 137), o Programa do XI Governo Constitucional expressava que era objetivo dessa reforma a "[...] multiplicação acelerada da oferta de formação profissional e profissionalizante quer no âmbito da reformulação do ensino secundário e da expansão do ensino superior politécnico, quer pelo apoio à implantação de uma rede de escolas profissionais, de iniciativa eminentemente local".

Constatou-se, na década de oitenta, elevado incremento de alunos a frequentar as vias profissionalizantes. Foi então criado, em 1989 o subsistema de escolas profissionais, com "tutela mista entre o Ministério da Educação e outros promotores públicos ou privados" (BARROSO, 2003, p. 71). Esta oferta pretendeu permitir aos alunos o acesso a um diploma profissional de certificação de qualificação (técnicos intermédios) equivalente ao diploma do ensino secundário para efeitos de prosseguimento de estudos (CERQUEIRA; MARTINS, 2011). Ao final da década de 90, as escolas profissionais consolidaram-se como instituições educativas (Decreto-Lei no 1998a) e enfatizaram-se as articulações, por um lado, entre a estrutura escolar e a formação profissional, e por outro, entre as organizações escolares e as instituições económicas, profissionais, associativas e socioculturais (RIBEIRO, 2014).

Em 2003, a reforma do ensino secundário preocupou-se com a consolidação do ensino profissional. Então, a partir de 2004, o ensino profissional, particularmente o ensino profissional/vocacional de nível 4, foi estendido a toda a rede pública e privada de escolas secundárias e escolas profissionais, como acima referido. Estabeleceu-se também a escolaridade obrigatória de 12 anos, por 
meio da Lei no 85/2009 que procedeu de fato, no seu arto $5^{\circ}$, à terceira alteração da Lei de Bases do Sistema Educativo. A introdução da escolaridade obrigatória no ensino secundário, na opinião de Ribeiro (2014), constituiu-se como uma das principais alterações ao sistema educativo, com a expansão e diversificação das ofertas formativas profissionalizantes, cuja entrada em vigor, em 2012, veio reforçar a criação de novas ofertas educativas de nível básico e secundário.

\section{Procedimentos metodológicos}

Com vistas a identificar o que a comunidade científica em Portugal investiga acerca da educação profissional recorreu-se a análise de trabalhos acadêmicos - artigos apresentados em eventos científicos, artigos publicados em revista, capítulos de livros, dissertações e teses - publicados entre 2010 e 2016 e que se encontram disponíveis em repositórios de quinze universidades ${ }^{3}$ e sete outras instituições ${ }^{4}$. A busca foi realizada no período de abril a junho de 2017 com o uso de descritores ou palavras-chave: educação profissional, cursos técnicos, formação de professores, formação docente.

Na primeira etapa do estudo, depois de localizados os trabalhos, leram-se os resumos para identificar aqueles que, efetivamente, tratavam da educação profissional, visto que a busca pelo uso conjugado das palavras "educação" e "profissional" identificou em cada repositório, trabalhos que tratavam de educação e de profissionalização, sem, no entanto, referirem-se à educação profissional. Essa tarefa foi exaustiva e daquele universo foram selecionados 22 trabalhos que constituíram o corpus deste estudo, que Bardin (2002, p. 128) identifica como o "[...] conjunto dos documentos tidos em conta para serem submetidos aos procedimentos analíticos". Para facilitar a leitura neste artigo optou-se por identificar os trabalhos (T1, T2, T3, etc.) por números em ordem cronológica (por ano) e dentre os do mesmo ano a sequência foi aleatória.

Na segunda etapa do estudo, analisaram-se os resumos para neles identificar os principais elementos constitutivos de um texto desse gênero, ou seja: temática central, objetivos, referencial teórico, metodologia (tipo de estu- do, técnica, instrumentos de recolha de dados, sujeitos pesquisados), resultados e conclusões. Entretanto, constatou-se que a maioria dos resumos não continha essas informações completas e foi necessário localizar e analisar os trabalhos na íntegra, especialmente a introdução, a metodologia e as conclusões. Registre-se, porém, que quatro trabalhos $(\mathrm{T} 12, \mathrm{~T} 14, \mathrm{~T} 15, \mathrm{~T} 19)$ estavam em acesso restrito, o que não permitiu completar a análise, que foi feita apenas com os dados do resumo.

$\mathrm{Na}$ terceira etapa, foi realizada a leitura flutuante (BARDIN, 2002) do conteúdo registrado nas produções e os elementos transcritos para uma planilha por meio do Microsoft Excel visando facilitar a categorização, que foi realizada por meio da análise de conteúdo, que Bardin (2002, p. 46) conceitua como

Um conjunto de técnicas de análise das comu-
nicações que, através de procedimentos siste-
máticos e objetivos de descrição do conteúdo
das mensagens, visa obter indicadores (quan-
titativos ou não) que permitam a inferência de
conhecimentos relativos às condições de pro-
dução e de recepção (variáveis inferidas) destas
mensagens. Assim, procurou-se verificar a presença de ideias que se repetiam por meio de vocábulos com o mesmo sentido. Em seguida, procedeu-se a exploração do material, agrupando os relatos que continham ideias semelhantes, procedendo-se à codificação de unidades de registro em categorias de análise. Posteriormente fez-se o tratamento dos resultados, inferência e interpretação, ou seja, procurou-se analisar o conteúdo expresso constituindo as seguintes categorias centrais: quem produz (dados de autoria); o que se produz (objetivos/temáticas/conclusões); como se produz (metodologia utilizada).

Ademais, para investigar as características/perfil dos profissionais que pesquisam sobre educação profissional em Portugal consultou-se as plataformas De Gois (Portugal) e a Plataforma Lattes (Brasil), além dos sites de universidades buscando informações sobre os autores, tais como: nível de formação, vínculo às universidades portuguesas e suas nacionalidades. 


\section{Apresentação e discussão dos resultados}

O corpus do presente estudo encontra-se coligido no Quadro 1. Contatou-se que as dissertações de mestrado e teses de doutoramento são predominantes e que a distribuição de todas as publicações é praticamente uniforme ao longo do período, pois em média houve a elaboração de três trabalhos por ano, exceto em 2010 e 2012, onde houve um e seis, respectivamente.

Quadro 1- Produção acadêmica sobre educação profissional

\begin{tabular}{|c|c|c|c|c|c|}
\hline $\mathrm{N}^{\circ}$ & Ano & $\begin{array}{l}\text { Tipo de } \\
\text { produção }\end{array}$ & Título & Autor/es & Instituição \\
\hline T1 & 2010 & Dis & $\begin{array}{l}\text { Ensino Profissional: Expectativas dos Novos Alunos e Avaliação do } \\
\text { Desempenho dos Formadores. }\end{array}$ & Gonçalves, Bruno Alberto Matos & $\begin{array}{l}\text { Universidade } \\
\text { De Trás-Os- } \\
\text { Montes e Alto } \\
\text { Douro. }\end{array}$ \\
\hline $\mathrm{T} 2$ & 2011 & Dis & $\begin{array}{l}\text { Escolhas escolares: entre o insucesso e o abandono. Estudo de caso } \\
\text { numa escola profissional agrícola. }\end{array}$ & Gonçalves, Maria Aurora Ferreira & Açores \\
\hline T3 & 2011 & $\begin{array}{l}\text { Artigo } \\
\text { revista }\end{array}$ & $\begin{array}{l}\text { A consolidação da Educação e Formação Profissional na Escola Se- } \\
\text { cundária nos últimos } 50 \text { anos em Portugal. }\end{array}$ & $\begin{array}{l}\text { Cerqueira, Maria de Fátima; } \\
\text { Martins, Alcina M. de Oliveira }\end{array}$ & $\begin{array}{l}\text { Universidade } \\
\text { Lusófona }\end{array}$ \\
\hline T4 & 2011 & $\begin{array}{l}\text { Capítulo } \\
\text { Livro }\end{array}$ & $\begin{array}{l}\text { A formação em contexto de trabalho: o papel supervisivo das esco- } \\
\text { las de ensino profissional. }\end{array}$ & $\begin{array}{l}\text { Leal, SusanaMira; Camarinha, } \\
\text { Hélder }\end{array}$ & Açores \\
\hline T5 & 2012 & $\begin{array}{l}\text { Artigo } \\
\text { revista }\end{array}$ & $\begin{array}{l}\text { Competências e habilidades na formação docente para o ensino } \\
\text { técnico profissional. }\end{array}$ & $\begin{array}{l}\text { Belli, Jurema I. R.; Henriques, } \\
\text { Susana; Barros, Daniela M. Vieira }\end{array}$ & $\begin{array}{l}\text { Univ. Aberta } \\
\text { de Lisboa }\end{array}$ \\
\hline T6 & 2012 & $\begin{array}{l}\text { Artigo } \\
\text { revista }\end{array}$ & $\begin{array}{l}\text { Políticas de educação profissional no mundo globalizado: o caso } \\
\text { brasileiro - abordagem comentada. }\end{array}$ & $\begin{array}{l}\text { Oliveira. Maria Rita Neto Sales, } \\
\text { Viana, Isabel Carvalho }\end{array}$ & Uminho \\
\hline T7 & 2012 & $\begin{array}{l}\text { Artigo } \\
\text { Evento }\end{array}$ & $\begin{array}{l}\text { Currículo, Formação e Trabalho Docente na Educação Profissional } \\
\text { de Jovens e Adultos. }\end{array}$ & $\begin{array}{l}\text { Pacheco, José Augusto Guima- } \\
\text { rães, Rocha, Edilene }\end{array}$ & Uminho \\
\hline T8 & 2012 & Tese & $\begin{array}{l}\text { A reestruturação curricular da educação profissional no Brasil face } \\
\text { às diretrizes nacionais e Internacionais e a participação dos agentes } \\
\text { curriculares: o caso do IFRN. }\end{array}$ & Silva, Luzimar Barbalho da & Uminho \\
\hline T9 & 2012 & Tese & $\begin{array}{l}\text { Contextos e oportunidades de formação e de desenvolvimento } \\
\text { profissional: um estudo com professores de informática. }\end{array}$ & $\begin{array}{l}\text { Correia, Ermelinda de Lurdes } \\
\text { Salgado }\end{array}$ & Uminho \\
\hline T10 & 2012 & Dis & $\begin{array}{l}\text { Ensino profissional na escola secundária: gestão adequada a um } \\
\text { resultado mais eficaz. }\end{array}$ & Jerónimo, Maria Teresa P. da Luz & Algarve \\
\hline T11 & 2013 & Dis & $\begin{array}{l}\text { Educação e trabalho: trajetórias de formação e de inserção profis- } \\
\text { sional na vida ativa: um estudo de caso sobre os cursos profissio- } \\
\text { nais numa escola pública portuguesa. }\end{array}$ & $\begin{array}{l}\text { Silva, Daniela Sofia Marinho } \\
\text { Nascimento da }\end{array}$ & Uminho \\
\hline T12 & 2013 & Dis & $\begin{array}{l}\text { Motivação e gestão dos recursos humanos dos institutos médios } \\
\text { técnicos de Luanda no quadro da reforma educativa. }\end{array}$ & Jorge, Victor José & Evora \\
\hline T13 & 2013 & $\begin{array}{l}\text { Artigo } \\
\text { Evento }\end{array}$ & $\begin{array}{l}\text { Contribuição do curso de especialização na prática docente da } \\
\text { educação profissional de jovens e adultos. }\end{array}$ & $\begin{array}{l}\text { Costa, Maria Alexandra Ribeiro } \\
\text { Pinto da; Viana, Isabel de Car- } \\
\text { valho }\end{array}$ & Uminho \\
\hline T14 & 2014 & $\begin{array}{l}\text { Artigo } \\
\text { Evento }\end{array}$ & $\begin{array}{l}\text { Formação e atuação de professores bacharéis no ensino médio in- } \\
\text { tegrado à educação profissional: o caso do IFRN-Instituto Federal } \\
\text { de Educação, Ciência e Tecnologia, RN/Brasil. }\end{array}$ & $\begin{array}{l}\text { Barros, Rejane Bezerra } \\
\text { Viana, Isabel Carvalho; Ramalho, } \\
\text { Betania Leite. }\end{array}$ & Uminho \\
\hline T15 & 2014 & \begin{tabular}{|l|} 
Capítulo \\
livro
\end{tabular} & $\begin{array}{l}\text { Quatro décadas de Portugal democrático. O que oferece aos jo- } \\
\text { vens a formação profissional de nível secundário? }\end{array}$ & Antunes, Fátima; Sá, Virgínio & Uminho \\
\hline T16 & 2014 & Tese & $\begin{array}{l}\text { Gestão empresarial, educação profissional e cidadania: um estudo da } \\
\text { gestão em escolas de ensino médio integrado no estado do Ceará. }\end{array}$ & Gonçalves, Zirlânea da Silva & Uminho \\
\hline T17 & 2014 & Dis & $\begin{array}{l}\text { Caracterização organizacional das escolas técnicas profissionais de } \\
\text { saúde em Angola: caso do estudo à ETPS de Luanda. }\end{array}$ & Tomás, Diodeth Mara Francisco & Evora \\
\hline T18 & 2015 & Dis & $\begin{array}{l}\text { Docentes de cursos profissionais: que representações face ao ensino } \\
\text { profissional? - um estudo realizado numa escola secundária do Algarve. }\end{array}$ & Correia, Hélder José Fernandes & Algarve \\
\hline T19 & 2015 & Tese & $\begin{array}{l}\text { Novas competências e habilidades na formação docente para o ensi- } \\
\text { no técnico profissional: um estudo comparado entre Brasil e Portugal. }\end{array}$ & Belli, Jurema lara Reis & $\begin{array}{l}\text { Aberta de } \\
\text { Lisboa }\end{array}$ \\
\hline T20 & 2016 & $\begin{array}{l}\text { Artigo } \\
\text { Evento }\end{array}$ & $\begin{array}{l}\text { Acesso à formação profissional e espaço de oportunidade: um es- } \\
\text { tudo na Região Autónoma dos Açores. }\end{array}$ & $\begin{array}{l}\text { Lalanda-Gonçalves, Rolando } \\
\text { Caldeira, Suzana Nunes; Silva, } \\
\text { Osvaldo }\end{array}$ & Açores \\
\hline T21 & 2016 & Tese & $\begin{array}{l}\text { O IFRN no âmbito das políticas públicas de expansão dos institutos } \\
\text { federais no Brasil: uma abordagem organizacional sobre o proces- } \\
\text { so de democratização do ensino médio e superior, a partir das re- } \\
\text { presentações de alunos, professores e gestores. }\end{array}$ & Oliveira, André Luiz Ferreira de & Uminho \\
\hline T22 & 2016 & Dis & Formação profissional nos Açores: uma análise empírica. & Braga, José António de Sousa & Açores \\
\hline
\end{tabular}


Dos dados inventariados na produção da comunidade científica portuguesa sobre educação profissional (EP) emergiram três categorias: A) autores de trabalhos sobre $E P, B$ ) temáticas abordadas no âmbito da EP e C) políticas e currículo na EP.

\section{A) Autores de trabalhos sobre educação profissional}

Os vinte e dois trabalhos analisados foram produzidos por trinta autores, cuja titulação é a seguinte: oito mestrandos, um mestre, sete doutorandos, dois em pós-doutoramento e doze professores doutores de instituições de ensino superior. Observa-se que o maior número de professores doutores explica-se pelo fato de atuarem como orientadores de investigações que resultaram na elaboração de artigos nos quais assumem a coautoria.

A nacionalidade dos autores constituiu-se de: dezenove portugueses, nove brasileiros e dois angolanos. Chama a atenção o alto índice de brasileiros que estudam em universidades portuguesas na condição de pós-doutoramentos (dois), em doutorado sanduíche (um) e doutoramento pleno (seis). Note-se no Quadro 1 que, dentre as cinco teses produzidas em Portugal, quatro tiveram como autor, objeto de estudo e lócus as instituições de educação profissional brasileiras (T8, T16, T19, T21), temas também presentes nos três artigos em anais de eventos $(\mathrm{T} 7, \mathrm{~T} 13, \mathrm{~T} 14)$ e dois artigos em revistas (T5 e T6).

Essa situação é resultado do processo de internacionalização das universidades que, provocado pela globalização da economia, exige das instituições de ensino superior a adaptação aos desafios por ela impostos, criando um ambiente acadêmico internacional. Assim, o papel das universidades amplia e complexifica, pois precisa formar cidadãos mais bem preparados para atuar no mercado de trabalho globalizado e, além disso, colaborar na geração e divulgação de investigações básicas e aplicadas que promovem a inovação das diversas áreas do conhecimento.

Na Europa, a internacionalização das universidades, para além de outros mecanismos, foi também impulsionada com o Processo de Bolonha, constando na agenda política da União Europeia, em que a mobilidade e reconhecimento de diplomas estrangeiros são inerentes ao próprio processo. Segundo Colussi; Costa; Silva (2015, p. 5) a mobilidade acadêmica proporciona outras grandes vantagens:

[...] atualmente a internacionalização vai para
além da pura mobilidade acadêmica e começa
a abranger de forma mais generalizada o desen-
volvimento do sistema de ensino superior. Como
tal, este aspecto tornou-se transversal: a mobili-
dade física de diferentes tipos é vista como uma
atividade que beneficia mais do que estudantes
e docentes, também (e essencialmente) um con-
junto alargado de partes interessadas dentro da
comunidade académica e empresarial - estu-
dantes, técnicos, docentes, empregadores, insti-
tuições, economias, etc. A mobilidade deixou de
ser sinónimo de internacionalização; ela é atual-
mente reconhecida como um veículo para uma
internacionalização que deve beneficiar a comu-
nidade local e global de uma forma muito mais
abrangente e complexa.

Ainda segundo estas autoras, estudos recentes desenvolvidos no Reino Unido, Holanda, Dinamarca e França apontaram o impacto positivo da mobilidade dos estudantes internacionais, o que tem sido usado como argumento para apoiar as estratégias de internacionalização das universidades, como a destinação de bolsas, retirada de restrições a visto para estudantes, criação de programas de financiamento bilaterais para melhoria das parcerias institucionais, criação de grandes consórcios de pesquisa e implantação de campi universitários em países emergentes.

No caso de Brasil, segundo dados da CAPES, a partir de 2001 até 2015 houve incremento no financiamento de bolsas no exterior, especialmente entre 2012 a 2015. De acordo com dados da Geocapes (2015) os Estados Unidos e Portugal são os dois países que mais receberam bolsistas em doutorado pleno, doutorado sanduíche e pós-doutorado (Quadro 2). As áreas de estudos não estão discriminadas, de modo que não é possível apontar uma razão para este fato. 
Quadro 2 - Países com maior número de bolsistas brasileiros - 2015

\begin{tabular}{|c|c|c|c|c|}
\hline PAIS & 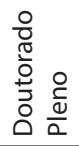 & 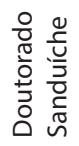 & $\begin{array}{rl} & \frac{0}{0} \\
& \frac{\pi}{0} \\
1 & 0 \\
00 & 0 \\
0\end{array}$ & $\begin{array}{l}\bar{\pi} \\
\text { 00 } \\
\end{array}$ \\
\hline Estados Unidos & 449 & 1368 & 270 & 2087 \\
\hline Portugal & 552 & 714 & 198 & 1464 \\
\hline França & 213 & 682 & 191 & 1086 \\
\hline Reino Unido & 428 & 348 & 115 & 891 \\
\hline Espanha & 194 & 559 & 96 & 849 \\
\hline Alemanha & 202 & 256 & 106 & 564 \\
\hline Canadá & 103 & 228 & 50 & 381 \\
\hline Itália & 69 & 213 & 49 & 331 \\
\hline Holanda & 55 & 123 & 40 & 218 \\
\hline Austrália & 59 & 103 & 24 & 186 \\
\hline
\end{tabular}

Fonte: produzido pelas autoras a partir dos dados da Geocapes disponíveis em: http://geocapes.capes.gov.br/geocapes2/

Por fim, verificou-se que os pesquisadores advêm de diferentes instituições de ensino superior (Quadro 1): 10 da Universidade do Minho; 4 da Universidade dos Açores; 2 da Universidade do Algarve; 2 da Universidade de Évora; 2 da Universidade Aberta de Lisboa; 1 da Universidade De Trás-Os-Montes e Alto Douro; 1 da Universidade Lusófona do Porto.

O dado que se destaca é referente à Uminho, que concentra $45 \%$ dos trabalhos produzidos acerca da educação profissional, sendo que sete foram produzidos por autores brasileiros que estudaram nesta universidade. Há três trabalhos identificados com autor único ( $T 8, T 16$, T21) e quatro em coautoria com os orientadores (T6, T7, T13, T14). Estes dados mostram o interesse da Universidade do Minho na educação profissional e, por outro lado, a participação de brasileiros nestes trabalhos demonstra a abertura desta universidade à colaboração com instituições brasileiras.

Na próxima seção estão apresentados os dados relativos às temáticas que têm sido pesquisadas sobre educação profissional no país.

\section{B) Temáticas abordadas no âmbito da educação profis- sional}

Visando identificar sobre o que investiga a comunidade científica sobre educação profissional analisaram-se os objetivos, temáticas e conclusões dos estudos e os resultados permitiram identificar as seguintes categorias: a) caracterização dos cursos de EP; b) formação de professores da EP; c) políticas e currículo da EP no Brasil e/ou Portugal; d) gestão administrativa e/ou pedagógica dos cursos de EP.

\section{a) Caracterização dos cursos de educação profissional}

Sete estudos (T1 - T2 - T10 - T11 - T18 - T20 - T22, ver Quadro 1) caracterizam-se por serem pesquisas de caráter exploratório dos quais todos, exceto o T20, são dissertações de mestrado. Os sete trabalhos foram realizados por autores portugueses sobre educação profissional de escolas secundárias portuguesas, bem distribuídas geograficamente: duas na região Norte - Viana do Castelo e Ponte de Lima; uma na região Centro - Lisboa; duas na região Sul - Algarve, e duas na região autônoma dos Açores. Estes estudos ocuparam-se em desvelar as características dos cursos profissionais secundários em relação ao perfil do alunado, razões de ingresso, expectativas e avaliação dos resultados/impactos pessoais e sociais.

Por outro lado, diferenciam-se pela ótica de análise: dois trabalhos (T1 e T2) tomaram como fonte de referência as opiniões dos alunos; dois (T10 e T11) são mistos, no sentido de incluírem as opiniões dos alunos, diretores e coordenadores de cursos técnicos; um (T18) baseia-se nas representações dos professores; e dois (T20 e T22) investigam jovens residentes nas comunidades lócus das pesquisas.

O trabalho T18 parte das representações dos docentes, que atuam na escola de educação profissional com o intuito de perceber, dentre outros aspectos, as razões da escolha dos cursos pelos alunos, a adequação do currículo ao mercado de trabalho, os preconceitos, constrangimentos e vantagens dos cursos de educação profissional, além do grau de motivação dos docentes e suas necessidades de formação para a docência. $O$ estudo concluiu que os professores apontam como razões para a escolha dos cursos, pelos alunos, a dupla certificação que lhes permite ingressar mais cedo no mercado de trabalho e continuar os estudos na área de especialização 
do curso profissional, fator considerado como vantagem distintiva da EP; dividiram as opiniões em relação a adequação do currículo dos cursos às exigências do mercado de trabalho; identificam como preconceitos associados a EP a crença de que se tratam de curso mais fáceis e frequentados por alunos de baixo rendimento escolar, os "excluídos do sistema"; como constrangimento constatam que há desajustes entre o que os alunos aprendem nos cursos e o que deles é esperado pelas entidades empregadoras, já que no contexto de trabalho os alunos se defrontam com a exigência de realização de multitarefas; consideram-se motivados para trabalhar nesses cursos, especialmente os que possuem maior tempo de lecionação e ainda ressentem-se da falta de formação (inicial e contínua) para as atividades da docência.

As pesquisas realizadas com alunos $(\mathrm{T} 1, \mathrm{~T} 2)$ e as mistas (T10 e T11), de modo geral, convergem em termos de objetivos, temáticas abordadas e conclusões. São temáticas recorrentes à contextualização histórica e legislativa da formação e da EP em Portugal, relação educação e trabalho, impactos da formação profissional e gestão curricular e em relação aos objetivos e conclusões convergem nos seguintes aspectos: razões para o ingresso nos cursos de EP e suas expectativas, o perfil do alunado, avaliação da qualidade da formação recebida e impactos dos cursos, em diversas dimensões pessoais e sociais.

Entre as razões para o ingresso no curso e as expectativas dos alunos prevalece, tal como apontado pelos docentes, a dupla certificação porque ao mesmo tempo em que lhes antecipa o ingresso no mercado de trabalho, oportuniza o prosseguimento dos estudos, ou seja, a EP é considerada importante via para melhorar as perspectivas de vida.

O alunado desses cursos, segundo as pesquisas, é constituído majoritariamente por indivíduos com histórico de insucesso escolar e sobre a EP se mantém o preconceito de curso de "segunda classe", pois é a oferta destinada àqueles que não se identificam com o tradicional sistema regular de ensino, o que agrava a imagem negativa que se tem desta modalidade de ensino.
A avaliação, pelos alunos, da qualidade da formação recebida nos cursos é positiva, já que o grau de satisfação dos formandos em geral é satisfatório em relação à escola e aos seus professores, e consideram que a EP proporciona boas oportunidades de emprego. Porém, também são mencionados nos trabalhos como necessidades prementes a ampliação dos recursos materiais e equipamentos, o investimento na integração curricular e maior valorização da formação em contexto de trabalho como estratégia de integração profissional.

No que tange aos impactos desses cursos nas dimensões pessoais e sociais os resultados não foram conclusivos porque esse tipo de informação dificilmente pode ser auferida em estudos exploratórios baseados em opiniões dos seus atores (alunos e professores). O T11, entretanto, concluiu que a maioria dos alunos já exerce atividade profissional e um número significativo deles atua na área do curso, embora com contratos a termo e salários precarizados. $\mathrm{O}$ tempo necessário para ingresso no mercado de trabalho após a conclusão do curso é em torno de seis meses.

A pesquisa relatada no T20 foi realizada com 1485 indivíduos de 15 a 34 anos com o objetivo de verificar a frequência ou não em cursos de EP e concluiu pela existência de três grupos:

- Com perfil de formação restrita: jovem com baixo nível de escolaridade que se evadiram da escola e ingressaram muito cedo no mercado de trabalho, geralmente estão desempregados ou desempenham funções desqualificadas e retornam a EP nos cursos de pesca e construção civil;

- Com perfil aberto de formação: em melhor grau de escolaridade, ou seja, ensino secundário ou superior, saíram da escola entre os 18 a 24 anos, estão empregados exercendo atividades nas áreas administrativas e de serviços e já frequentaram cursos de EP;

- Com perfil de formação contínua: jovens que nunca trabalharam, não têm experiência profissional, com idade entre 15 a 19 anos, que estudam na EP em cursos 
ligados a informática e multimídia e pretendem fazer estágio na área, após a conclusão do curso.

Por fim, o T22 foi realizado com residentes em diversas ilhas dos Açores com a finalidade de identificar a percepção dos participantes acerca do impacto da formação profissional e os resultados indicam que, quanto mais elevada é a faixa etária, maior é a percepção de que os cursos lecionados nas escolas profissionais dos Açores não estão enquadrados com as atividades que mais contribuem para a riqueza da região e que, se obtivessem mais formação, as oportunidades de trabalho dos inquiridos seriam melhores.

\section{b) Formação de professores da educação profissional}

Seis trabalhos (T5, T7, T9, T13, T14, T19, ver Quadro 1) fizeram referência à formação de professores da EP nos objetivos, temáticas abordadas e conclusões. $\mathrm{O}$ artigo (T5) e a tese (T19) foram produzidos pela mesma autora, sendo que o primeiro em parceria com as orientadoras, e tratam da mesma temática, ou seja, as políticas brasileiras e portuguesas de formação de professor com o intuito de identificar as competências e habilidades necessárias para o exercício da docência e, assim, apontar subsídios para a proposição de novas práticas de formação docente na educação profissional. Nos trabalhos discutiram as noções de competência, habilidades e profissionalização docente, a formação de professores para a educação profissional e analisaram documentos oficiais dos países envolvidos, que resultou na identificação de dezessete eixos determinando as diferentes dimensões e perspectivas de formação. Como conclusão as autoras apresentaram uma Proposta de Matriz Lusobrasileira de "Competências e Habilidades" para a Formação Docente no Ensino Técnico.

Os artigos T7 e T13 centraram-se na formação de professores para a educação profissional de jovens e adultos no Brasil. O primeiro resultou de projeto de pós-doutoramento que analisou as relações entre currículo, formação e trabalho docente; o segundo, fruto de tese então em andamento, investigou as contribuições que a frequência num curso de especialização em Educação de
Jovens e Adultos oportunizou para a qualificação da prática docente. Neles estão presentes reflexões acerca das políticas de formação de professores para a educação profissional no Brasil, o Programa Nacional de Integração da Educação Profissional com a Educação Básica na Modalidade de Educação de Jovens e Adultos (PROEJA), além de questões relativas ao currículo. Quanto aos resultados, T13 apresentou pesquisa em andamento e por isso não conclusiva, enquanto que T7 concluiu que "o desenvolvimento curricular dos cursos técnicos integrados PROEJA ainda tem se configurado como parte integrante de políticas curriculares homogêneas e desiguais" (p. 12).

A formação e o desenvolvimento profissional de professores bacharéis que atuam na educação profissional em Portugal e no Brasil foram investigados no T9 e T14, respectivamente, analisando como eles respondem às necessidades formativas para o exercício da docência, tomando como referência a percepção dos próprios professores. Dentre as temáticas abordadas estão políticas e legislação acerca da formação inicial e continuada de professores da educação profissional nos países pesquisados e o desenvolvimento profissional, em seus múltiplos aspectos: conceito, modelos, estratégias, fatores que nele influenciam e desenvolvimento profissional e as fases da carreira. As conclusões apontam que nos dois países a formação inicial desses profissionais não inclui a preparação para a docência, que os professores reconhecem a importância dessa formação, porém mais como uma mais valia, um plus, do que necessidade premente. No caso do Brasil, os dados apontam que as instituições de ensino, quando da elaboração do trabalho (2014), priorizavam a infraestrutura física, equipamentos, e contratação de pessoal, sem a preocupação central com o perfil de formação dos professores, razão pela qual as autoras consideram importante a criação de programas de formação continuada. Em Portugal, conclui a autora, os investigados valorizam as oportunidades de desenvolvimento profissional coletivo, colaborativo, que se realiza no contexto do trabalho.

Os dados apontam que o tema formação de professores para a educação profissional é majoritariamente objeto de pesquisa de doutorandos brasileiros, já que somen- 
te uma doutoranda tem nacionalidade portuguesa. Os cursos técnicos de nível secundário - em suas várias dimensões - são essencialmente objetos de estudo das dissertações de mestrado, mas a formação de professores não constituem prioridades dos doutorandos e pós-doutorandos portugueses o que pode estar ligada ao fato de que a formação desses professores, no país, não se diferencia daquela dos professores em geral, ou seja, o tema formação de professores pode estar na agenda de investigação da comunidade científica portuguesa sem, contudo, particularizar o processo de formação dos professores da educação profissional.

\section{c) Políticas e currículo da EP no Brasil e/ou em Portugal}

São cinco os trabalhos sobre as políticas públicas e curriculares, (T3, T6, T8, T15, T21, Quadro 1), dois referentes a Portugal e três ao Brasil. No primeiro grupo, estão um artigo (T3) e um capítulo de livro (15) de cunho teórico: o T3 revisa as principais reformas do sistema educativo português que contribuíram para a consolidação da política para a educação e formação no país; e o T15, que tem o escopo de apresentar um balanço do que, após quatro décadas de democracia em Portugal, se oferece aos jovens na educação profissional secundária, comparando com o horizonte das promessas de democratização. Os autores reconhecem como positiva a ampliação da oferta dos cursos de educação profissional, especialmente após os anos 2000, quando houve redução das taxas de reprovação e elevação das taxas de conclusão dos cursos. Essa via de escolarização, entretanto, passou a ser vista como possibilidade de inserção no trabalho e acabou por desviar os jovens do caminho para o ensino superior e,

Hoje, essa ampliação das oportunidades institucionais começa a ficar em questão, a educação profissional está a caminho do acantonamento como uma via terminal de massas e ameaça converter-se numa resposta educativa voltada para a restrição de oportunidades; nesse sentido, torna-se mais visível o resfriamento de aspirações à continuidade de estudos, em favor de uma orientação política de controlo social e conformidade a um projeto de subdesenvol- vimento e incoesão da sociedade portuguesa (T15, resumo).

No segundo grupo, foram incluídos dois trabalhos que tratam de políticas curriculares no Brasil: T6 explicitou as políticas curriculares para a Educação Profissional Técnica de Nível Médio no Brasil; e T8 analisou os processos de reestruturação do currículo da Educação Profissional em face das mudanças nas diretrizes nacionais e internacionais enfocando a participação dos agentes curriculares. Como temas, abordam a retrospectiva histórica da evolução das políticas curriculares no Brasil a partir dos anos de 1990 e as mudanças curriculares da Educação Profissional no mundo globalizado, especialmente na União Europeia, na América Latina e no Brasil.

Quanto aos resultados, no T6, as autoras concluem que as políticas curriculares brasileiras são caraterizadas pela tendência de ora afirmar e ora negar o ajuste à globalização e, via de regra, "caracterizam-se pelo seu caráter impositivo, que implica a sua definição por meio de decretos. A partir da década passada, esse caráter encontra-se mediado pela categoria conciliação" (T6, resumo). Já no T8, consta que os currículos da Educação Profissional no Brasil foram sendo alterados em 1995, 1997, 2004 e 2008 em função de reestruturação das políticas curriculares no país, ora de cunho mais participativo, ora mais impositivo. De modo geral os dados apontam que as mudanças curriculares provocaram impactos nas práticas institucionais e no fazer pedagógico docente, provocando diferentes desafios, mas também avanços.

Por fim, o T21 teve por objetivo retratar os impactos da expansão da Rede Federal de ensino no Brasil, tomando como lócus do estudo um Instituto Federal de Educação, Ciência e Tecnologia para analisar a representação organizacional e pedagógica dos atores da instituição. Para tanto apresenta as políticas educacionais a partir da década de 90, a trajetória de evolução da instituição, um panorama do sistema educacional atual (França, Alemanha, Reino Unido, Portugal, Brasil), os rankings de qualidade educacional e modelos e teorias organizacionais. Como resultado o T21 constatou a forte presença dos modelos organizacionais racional-burocrático, político e ambíguo 
e, dentre os efeitos causados pela expansão, identificou que os alunos dos cursos técnicos não prosseguem os estudos na instituição, preferindo ingressar nas universidades. Na interpretação do autor, isso ocorre devido às reformas e políticas decisórias, internas e externas à instituição, que acabaram por influenciar a oferta e a procura pelos cursos.

d) Gestão administrativa e pedagógica dos cursos de Educação Profissional

No presente estudo encontraram-se cinco trabalhos que abordam a gestão dos cursos técnicos profissionais ( $\mathrm{T} 4$, T12, T16, T17, Quadro 1), sendo um de Portugal (T4), um do Brasil (T16) e dois (T12, T17) de Angola.

O T4 investigou o processo de estágio nos cursos profissionais - em Portugal, chamado de Formação em Contextos de Trabalho (FCT), discutindo a importância da supervisão neste processo. Assim, analisou os regulamentos e inquiriu os supervisores da FCT nas escolas de ensino profissional da Região Autónoma dos Açores para identificar como são regulamentados e se desenvolvem. Nas conclusões, aponta que os regulamentos não definem com clareza os procedimentos de realização das atividades; que os orientadores/formadores, em sua maioria, não são da área técnica e admitem ter dificuldades de orientar os alunos, com poucas visitas de acompanhamento aos alunos, e as que ocorrem têm função mais avaliativa do que formativa.

OT16 focaliza-se no Brasil e analisa os principais desafios da proposta de formação para a cidadania mediante as diretrizes da gestão empresarial para cumprir a missão das Escolas Estaduais de Educação Profissional (EEEP), que é a formação escolar integrada a uma vivência de cidadania e protagonismo juvenil. Foi desenvolvido tendo como lócus as escolas de ensino médio integrado no estado do Ceará e as temáticas abordadas foram formação para a cidadania, Estado e as políticas educativas e de formação, a organização escolar e especificidades da gestão e as políticas públicas de educação no Ceará. Concluiu que a imagem da escola guarda correspondência com a concepção dos gestores e tende a promover dois tipos de formação: a primeira, perspectiva do "cidadão aprendente", caracteriza-se pelo estilo empresarial, gestão tecnocrata, produtivista e voltado para a aquisição de conhecimentos para inclusão no mundo do trabalho; a segunda, o "aprendente como cidadão" caracteriza-se pela gestão democrática que reconhece a importância da educação polivalente para a formação de cidadãos e preza pela geração da consciência crítica e estimula nos alunos a abertura ao sentido ético da existência na sociedade.

Dois trabalhos (T12 e T17) abordam a educação profissional em Angola em que T12 deteve-se a analisar os mecanismos de gestão de recursos humanos, especialmente como ocorre a motivação dos profissionais que atuam nas escolas, porém no resumo não constam os resultados da pesquisa e o trabalho não está disponível para acesso. Já o T17 analisa as características organizacionais de uma escola técnica de saúde no que se refere à missão e à formação profissional ofertada. Foram abordados temas como a história da educação em Angola, caracterização do sistema educativo, a realidade do país e a educação profissional naquele contexto, tendo como enfoque principal a educação profissional para a saúde e o papel do professor. As dimensões investigadas são: a) experiência profissional dos professores, concluindo que a maioria dispõe de experiência no ensino; b) identificação dos currículos existentes, constando que apenas os professores com maior tempo de docência na escola conhecem os currículos dos cursos na integralidade; c) os cursos lecionados: embora a escola ofereça doze cursos técnicos os professores mencionaram a existência de sete; d) formação de professores, sendo a maioria licenciada em enfermagem, porém não frequentam eventos de formação contínua ofertados pela escola; e) funcionamento da escola em termos de organograma, controle e fiscalização.

\section{C) Percursos metodológicos da produção acadêmica}

Foi analisado o percurso metodológico expresso no resumo, introdução e na metodologia dos trabalhos. Enfocamos a abordagem de pesquisa, os procedimentos adotados, sujeitos investigados e métodos de análise de dados. 
Os dados coletados indicam que, em relação à classificação da pesquisa quanto à abordagem do problema, dentre os vinte e dois trabalhos, dez a identificam como qualitativa ( $T 2, T 5, T 7, T 8, T 12, T 13, T 14, T 16, T 19, T 21)$, cinco como quanti-qualitativa ( $\mathrm{T} 4, \mathrm{~T} 9, \mathrm{~T} 10, \mathrm{~T} 12, \mathrm{~T} 17)$, seis não fazem referência à abordagem $(\mathrm{T} 1, \mathrm{~T} 3, \mathrm{~T} 6, \mathrm{~T} 15, \mathrm{~T} 18$, T20) e uma (T22) como quantitativa. Considerando as caraterísticas dessa abordagem de pesquisa apontadas por Bogdan; Biklen (1994), pôde-se concluir que também nos trabalhos que a identificam como quali-quanti prevalecem a análise qualitativa, já que:

a) Foram elaborados com dados cuja fonte direta é o ambiente natural e os próprios autores os coletaram;

b) Os dados apresentados nos trabalhos, em sua maioria, possuem caráter descritivo. Embora os autores tenham coletado dados passíveis de ser quantificados e expressos em tabelas e gráficos, isso não descaracteriza a pesquisa qualitativa, já que aqueles dados foram complementares e não representam a totalidade da pesquisa, que sempre incluiu dados descritivos;

c) A intencionalidade das pesquisas esteve ligada a problemas surgidos na prática profissional e, mais do que a preocupação com os resultados, os autores demonstraram interessarem-se mais pelo processo em si;

d) A análise dos dados foi realizada pelo método indutivo, que partiu da observação de casos particulares para chegar a conclusões;

e) O que moveu os autores não foi a busca de verdades passíveis de universalização, mas a compreensão dos significados dos dados, relacionando-os com o contexto em que foram gerados.

No que se refere à classificação das pesquisas quanto aos procedimentos adotados, constata-se que a maioria delas se caracteriza como de campo (17), três são identificadas como análise documental (T5, T6, T19) e duas (T3, T15) são bibliográficas. Considera-se relevante que as pesquisas sejam predominantemente de campo, pois demonstram a preocupação em ouvir os protagonistas do processo, ou seja, os professores e alunos que atuam na educação profissional. Nas 17 pesquisas de campo, o estudo de caso é o mais recorrente (nove trabalhos: T2, T7, T8, T11, T12, T13, T17, T18, T21). Há ainda duas (T9, T14) identificadas como investigação - ação e em seis deles (T1, T4, T10, T16, T20, T22) não foi possível localizar a técnica utilizada. Quanto ao lócus, as dissertações foram majoritariamente realizadas em escolas secundárias, enquanto as teses e artigos indicam a produção de dados em institutos federais brasileiros, especialmente nos estados do nordeste. Como exemplos, citam-se T8, T13, T14 e T21, realizados em Natal-RN; T16 no Ceará e T7 em Pernambuco.

Os instrumentos mais usuais na pesquisa de campo são os questionários, com 15 ocorrências (T1, T2, T4, T8, T9, $\mathrm{T} 10, \mathrm{~T} 11, \mathrm{~T} 13, \mathrm{~T} 14, \mathrm{~T} 16, \mathrm{~T} 17, \mathrm{~T} 18, \mathrm{~T} 20, \mathrm{~T} 21, \mathrm{~T} 22)$; entrevista, utilizada em 12 trabalhos (T2, T8, T9, T10, T11, T12, T13, T14, T16, T17, T18, T21); grupo focal em dois (T7, T14), observação em um (T13) e a produção de narrativas escritas/projeto de vida em um trabalho (T16). Entretanto, registre-se que apenas quatro pesquisas utilizaram um único instrumento de recolha dos dados ( $\mathrm{T} 12$ com entrevista e T1, T4, T20 com questionários). Houve ainda cinco pesquisas de campo (T4, T7, T8, T14, T16) em que os dados foram complementados com a análise documental.

Para identificar quem são os sujeitos investigados analisamos a composição das amostras nas 17 pesquisas de campo e os dados apontam que 12 foram realizadas com professores dos cursos técnicos (T4, T7, T8, T9, T10, T11, $\mathrm{T} 13, \mathrm{~T} 14, \mathrm{~T} 16, \mathrm{~T} 17, \mathrm{~T} 18, \mathrm{~T} 21)$, nove com gestores (T7, T8, $\mathrm{T} 11, \mathrm{~T} 12, \mathrm{~T} 13, \mathrm{~T} 16, \mathrm{~T} 17, \mathrm{~T} 18, \mathrm{~T} 21)$, oito envolveram alunos e egressos dos cursos ( $\mathrm{T} 1, \mathrm{~T} 2, \mathrm{~T} 8, \mathrm{~T} 10, \mathrm{~T} 11, \mathrm{~T} 13, \mathrm{~T} 16, \mathrm{~T} 21)$, a comunidade externa foi inquirida em dois (T20 e T22) e os representantes das empresas num único trabalho (T10). Da mesma forma que o relatado nos instrumentos de coleta de dados, nesse quesito também há a combinação de mais de uma categoria de investigados, sendo que nove trabalhos (T7, T8, T10, T11, T13, T16, T17, T18, T21) foram feitos com a participação de sujeitos de mais de uma categoria. 
Quanto ao número de sujeitos pesquisados, quando há o uso de questionário a amostra é variável: no caso de alunos envolveu entre 25 até 306; com professores entre 30 e 520 e a comunidade externa de 266 e 1485 . Quando se faz uso de entrevistas prevalece baixo número de sujeitos envolvidos, como 12 alunos e, com relação aos professores, variou entre 2 a 14.

No que concerne a análise de dados, os dados quantitativos foram analisados com o auxílio de programas como o SPSS (Statistical Package for the Social Science), utilizado em sete trabalhos (T1, T2, T8, T9, T10, T18, T21), a estatística descritiva e e-test, em dois trabalhos $(\mathrm{T} 1, \mathrm{~T} 11)$, o WebQDA em dois trabalhos (T13, T21), o ACM (T20) e a regressão binária (T22). Em quatro trabalhos estão ausentes essa informação $(\mathrm{T} 4, \mathrm{~T} 12, \mathrm{~T} 14, \mathrm{~T} 17)$.

As pesquisas de abordagem qualitativas fizeram uso de entrevistas e narrativas de projetos de vida que geraram dados descritivos e foi recorrente a análise de conteúdo de Bardin, sendo citado em dez trabalhos (T7, T9, T10, $\mathrm{T} 11, \mathrm{~T} 13, \mathrm{~T} 16, \mathrm{~T} 17, \mathrm{~T} 18, \mathrm{~T} 19, \mathrm{~T} 21)$ e a análise do discurso foi mencionada no T14. Pode-se ainda identificar a ausência de informações relevantes acerca do percurso metodológico adotado na produção dos resumos, notadamente nas dissertações.

\section{Conclusões}

O objetivo central deste trabalho foi conhecer como a comunidade científica portuguesa analisa a educação profissional tendo-se, para o efeito, consultado os repositórios institucionais, identificando diversos dados como o perfil dos pesquisadores, as temáticas abordadas e os encaminhamentos metodológicos adotados nos diversos estudos. A presente investigação aponta as seguintes conclusões:

a) A comunidade científica de Portugal é constituída por pesquisadores nacionais e estrangeiros, sobretudo por estudantes brasileiros que, graças ao processo de internacionalização do ensino, migram para o país onde realizam cursos de pós-graduação, seja o doutorado pleno, o estágio sanduíche ou o pós-doutorado;

b) Nesse cenário, relativo à educação profissional, destaca-se a Universidade do Minho, onde se concentra a maior parte da produção acadêmica em forma de artigos e teses de doutorado. As dissertações de mestrado distribuem-se uniformemente entre as universidades e seus autores são estudantes portugueses e angolanos;

c) Constatamos a ausência de pesquisas sobre os Cursos Técnicos Superiores, oferta educativa que caracteriza os institutos politécnicos nacionais presentes em quinze unidades localizadas em quase todo o território português;

d) O tema formação de professores para a educação profissional está pouco presente nas pesquisas, sendo objeto de estudo dos doutorandos de nacionalidade brasileira. A razão pode estar ligada ao fato de que a formação de professores para a educação profissional em Portugal não se diferencia da formação dos professores em geral, ou seja, o tema formação de professores pode estar na agenda de investigação da comunidade científica portuguesa sem, contudo, particularizar o processo de formação dos professores da educação profissional.

e) Quanto aos procedimentos metodológicos, prevalecem as pesquisas de abordagem qualitativa, de campo do tipo de estudo de caso. $\mathrm{O}$ uso de instrumentos de natureza quantitativa (questionários) geralmente é combinado com técnicas qualitativas, como, por exemplo, as entrevistas.

Partindo da premissa que a divulgação das pesquisas contribui para o avanço do conhecimento da área, esperamos que o presente estudo possa apontar indicadores do estado do conhecimento sobre a educação profissional em Portugal, podendo inspirar novas pesquisas. 


\section{Agradecimentos}

Este Estudo teve apoio do projeto Estratégico da FCT UID/ CED/00317/2013 e recebeu Fundos Portugueses através da FCT (Fundação para a Ciência e a Tecnologia) e cofinanciado pelo Fundo Europeu de Desenvolvimento Regional (FEDER) através do COMPETE 2020 - Programa Operacional Competitividade e Internacionalização (POCI) no âmbito do CIEC (Centro de Investigação em Estudos da Criança, da Universidade do Minho) com a referência POCI-01-0145-FEDER-007562.

O estudo também contou com o apoio do Instituto Federal de Educação, Ciências e Tecnologia do Rio Grande do Sul e da Capes por meio da bolsa do Programa de Doutorado Sanduíche no Exterior/Processo n 88881.132562/2016-01.

\section{Notas}

1 Quadro Nacional de Qualificações é um quadro de referência único para classificar todas as qualificações produzidas no sistema educativo e formativo português, independentemente das vias de acesso (QNQ, S/D).

2 No sistema de ensino português, licenciatura é o grau acadêmico atribuído não só pelos cursos de formação de professores (como no Brasil), mas também aos outros cursos do mesmo nível acadêmico (graduações, no Brasil).

3 Universidades: Repositorium (Uminho); RAP (Porto); Estudo geral (Coimbra), Repositorio.UL (Lisboa), Veritati (Católica Portuguesa); RDPC-UE (Évora); Sapientia (Algarve); DigitUMa (Madeira); Repositório Aberto (Um. Aberta); UTAD (Trás-os-Montes e Alto Douro); Ubibliorum (da Beira Interior), RUN (Nova de Lisboa); RUAc (Açores); Repositório da Universidade Técnica de Lisboa; ISCTE (Instituto Universitário de Lisboa).

4 DITED - Depósito de Teses e Dissertações Digitais; Repositório da Biblioteca Nacional de Portugal; RCAAP - Repositório Científico de Acesso Aberto de Portugal; NDLTD - Networked Digital Library of Thesis and Dissertations; SHERPA - Repositories and Service Providers; DIALNET; Cybertesis - Repositório de Tesis Digitales.

\section{Referências}

BARDIN, L. Análise de conteúdo. Lisboa: Edições 70, 2002.

BARROSO, J. Organização e regulação dos ensinos básico e secundário, em Portugal: sentidos de uma evolução. Educação \& Sociedade, 24, (82), 63-92, 2003. Disponível em: http://www. scielo.br/scielo.php. Acesso em: 17 abr. 2010.
BOGDAN, R.; BIKLEN, S. Investigação qualitativa em educação: uma introdução à teoria e aos métodos. Porto, Porto Editora, 1994.

BRASIL. Ministério da Educação. Coordenação de Aperfeiçoamento de Pessoal de Nível Superior. Distribuição dos discentes de Pós-Graduação no Brasil. Disponível em http://geocapes.capes.gov.br/geocapes2/. Acesso em: 05. jul. 2017.

CAMPOS, B. Formação de professores em Portugal. Lisboa, Instituto de Inovação Educacional, 1995.

CERQUEIRA, M. F.; MARTINS, A. M. O. A consolidação da educação e formação profissional na escola secundária nos últimos 50 anos em Portugal. Revista Lusófona de Educação, 17, 123145. 2011.

COLUSSI, E.; COSTA, A. S.; SILVA, R. Estratégias de internacionalização na Europa e no Brasil e o impacto do Programa Ciência Sem fronteiras. Projeto Elísios. Documento de TrabaIho no 2. Abril, 2015. Disponível em: http://www.uc.pt/iii/iniciativas/alisios/doc2. Acesso em: 03. jul. 2017.

MACHADO, L. R. de S. O desafio da formação dos professores para a EPT e PROEJA. Educação e Sociedade. Campinas, v. 32, n. 116, p. 689-704, jul-set.2011.

PORTUGAL. Ministério da Educação. Educação e formação em Portugal. 2007. Disponível em http://www.dgeec.mec.pt/np4 /97/\%7B \$clientServletPath\%7D/?newsld=147\&fileName=educ acao_formacao_portugal.pdf. Acesso em: 05. jul. 2017.

QNQ - Quadro Nacional de Qualificações. Disponível em: http://www.catalogo.anqep.gov.pt/Home/QNQ. Acesso em: 31. jul. 2017.

RIBEIRO, M. M. G. P. O ensino profissional de nível secundário em Portugal, 2000-2014. Quase mercado e isomorfismo. Tese de mestrado. Faculdade de Ciências Sociais e Humanas, Universidade de Lisboa. 2014.

Recebido em 05 de setembro de 2017.

Aceito em 10 de novembro de 2017. 
